\title{
A DO and Understand Approach to a Networking Course
}

\author{
Domingo Molina III \\ The University of Texas at Brownsville
}

\begin{abstract}
This paper presents the nuts and bolts of how a senior level computer science networking course is being successfully taught to students without requiring them to have any prior experience in networking. Because of the nature of indigenous industry, a pure theoretical approach to learning networking is inadequate to prepare the students for the job market. Just as lab work supports other computer science courses, the networking course requires the students to complete rigorous lab sessions leading to thorough understanding of the seven layers of ISO OSI model.

Throughout the lab assignments, which include several network installations, the students are shown practically how the theoretical principles learned in class apply to networking in the real world.

The lab assignments start with a simple examination of a network and its physical and logical topology. Students are exposed to the practical aspects of networking such as splicing cables, installing cable connectors, installing network interface boards, configuring drives, configuring a network in different topologies, selecting and configuring network hardware, and optimizing the overall network setup. After learning how to setup a network, students learn to install a network operating system, setup user accounts, provide access to different software packages, provide security, perform other administrative tasks, and troubleshoot the network at the hardware and software levels. Because of rigorous hands-on experience, students become extremely proficient in applied networking and obtain a deep understanding of the related theoretical aspects.
\end{abstract}

This paper begins by presenting the need and feasibility for offering such a networking course using a novel approach. It then details the contents of practical lab sessions that introduce students to the theoretical principles of networking. Finally, it presents the spinoffs of the course, such as earning certification as a Certified NetWare Engineer or Certified NetWare Administrator. 


\section{History of the Problem}

Using the concept used in business in which employees have input in decisions that concern them, we polled our junior and senior level computer science students to see what they felt would help them most in a networking course. ${ }^{9}$ Students indicated that they desired to obtain an applicable knowledge of networking that would lead to immediate employment opportunities after graduation. More than 80 percent of our university students depend on financial aid to attend the university and, because of a lack of finances, do not have access to a computer at home. Therefore, their familiarity with standalone computers is limited and their exposure to the design and architecture of a network is almost nonexistent. Because of these findings, the approach that many universities use in teaching networking in a theoretical manner needed to be put aside. However, the concepts on the basics of networking, the design, and development of a network needed to follow an approach approved by students and indigenous industry.

Because of the variety of network types available and the frequent need to interconnect them, an open architecture was developed for network developers. ${ }^{11}$ The formal data communications hierarchy model established for networks by the International Standards Organization (ISO) is the Open Systems Interconnection (OSI) reference model. ${ }^{4}$ During the course, the students were instructed that they were not to consider the OSI reference model as a program, a network operating system, or a protocol. It is to be viewed as a recommended set of guidelines for developing network technologies. ${ }^{3}$ For students with little understanding of how to develop a network, this concept is difficult to understand because they attempt to envision something physical, but for network developers who have an understanding of how to develop a network it is simply a model to guide them in network development. ${ }^{10}$ During this course, the concept of the OSI model was not rigorously introduced until the students had become comfortable with developing networks.

Many textbooks used in college courses approach networking in a theoretical direction at the beginning of the course and then conclude the course with a few network lab assignments. ${ }^{5}$ Some texts give students a presentation of networks and then follow-up with lab assignments. This approach has a tendency to lose students who need hands-on experience to understand the concepts of networking. ${ }^{3}$ Some courses tend to offer more data communications information and include some aspects of networking rather than concentrate exclusively on computer networking. Students often find that a large amount of the information they receive is a duplication of a communications course and feel shortchanged on computer networking. ${ }^{11}$ Other courses teach the physical aspects of networking and tend to reduce the theoretical aspects. ${ }^{6}$

\section{Designing the Course}

A networking course was designed to teach networking by using practical applications to support theoretical network principles taught in a typical college networking course. ${ }^{3}$ To help assure that the theoretical aspects of networks were covered, the Open Systems Interconnection model was used as a guide because "it was designed to provide companies with guidance and direction when developing methods of network communication, by establishing recommendations to be followed during the development of the network.". ${ }^{2}$ 


\section{Software Used}

Novell NetWare version 4.1 was selected as the network operating system software because of its current popularity throughout the networking world. ${ }^{7}$ The students needed a software environment that would prepare them to practical situations they will encounter on the job and would help them acquire tangible networking experience. ${ }^{8}$

\section{Textbook Selection}

The Novell Study Guide by New Riders reference book was selected as a textbook because it was a book that students would most likely find in environments with Novell networks in place such as offices, industries and other businesses. ${ }^{1}$ The book served to introduce the students to the practical approach of using a networking reference. In addition, the book enabled the course to expand beyond introductory networking topics.

\section{Assignments, Exams and Grading}

Lab assignments were performed using two students per group but lab exams were done and graded individually. All exams and lab assignments, except the comprehensive final exam, were graded individually and then averaged together by groups. The average of these grades was the grade given to each member of the group. This method of grading compelled group members to help each other do their best to earn a higher group average. In addition, short exams were given at every class meeting covering the material from the previous meeting and the assigned lab work. A comprehensive written final exam was given at the end of the semester to cover both the lecture and lab aspects of the course.

\section{Approach for Teaching the Course}

During the initial class meeting, a pre-exam over basic networking fundamentals such as networking jargon, hardware and software knowledge, installation, troubleshooting, and various administrative techniques showed that none of the students had significant networking knowledge. Afterwards, the class was shown a network hardware configuration without the software setup and the setup was explained in simple novice terms without using network jargon. This allowed the students to envision the finished network and what they were to develop and construct throughout the course.

The course was different from the typical networking course in that there was a heavy emphasis placed on hands-on lab work. Table 1 lists the activities covered in the course. All of the class meetings concluded with hands-on lab assignments that were designed to familiarize the students with practical aspects of networking to support the theoretical side. To help students retain their networking knowledge, lab assignments reiterated part of the previous assignments so that the students were forced to practice the lab procedures several times. Table 1 indicates that some activities were reiterated over several weeks. Several activities were repeated to give students additional practice. These repetitive activities led to student competency in these areas. For example, to ensure that students learned network installation, prior to each assignment, lab 
assistants removed the network software from each group's network and required the student group to reinstall the network software and any additional software needed to start and complete the assignment. Table III lists the specifications for hardware, software and groups.

During the network troubleshooting phase, the students were taught a logical and systematic approach whereby they checked for the most probable error first. The bus topology was used to help train students in the troubleshooting phase of the course since it has characteristically abrupt halts. Student groups were assigned networks with hardware and software problems to locate, analyze and repair. In addition to network utilities, items such as topologies were explained, the ARCnet and token-ring standards discussed, and transmission media investigated. Network media communications were explained and the students were exposed to the various network media through practical lab applications.

To gauge the course and the knowledge obtained, the students were encouraged to take the Novell Certified NetWare Administrators exam before the conclusion of the course and those passing the exam were awarded an "A" for the course grade. The exam is Novell's method for guaranteeing to prospective businesses that the people who work with networks have a thorough working knowledge of networks. ${ }^{1}$

\section{Open Systems Interconnection Model Explained}

During the course, the OSI model was explained to the students in layers. Table II shows the layers and when they were applied and examined. Most of these layers overlapped each other because in reality each one is closely related to the adjacent layers. Some of the layers were studied over more than one lab assignment. It was easier for the students to comprehend the seven layers of the OSI model after having practical experience. They discovered that they had been using the OSI model throughout the course and their assignments.

\section{Outcome}

Sixteen out of seventeen students completed the course. Nine students sat for the Novell Certified NetWare Administrators exam and all passed receiving certificates as Novell Certified NetWare Administrators.

\section{Conclusions}

The course structure was successful and will be used for teaching traditionally theoretical courses in a laboratory setting. Student evaluations of the course indicated unanimously that they enjoyed the hands-on experience and they felt that they assimilated a substantial amount of networking knowledge. In addition, they obtained a valuable amount of hands-on network experience that gave them confidence in their networking abilities.

Feedback from the Computer Science Department advisory board, consisting of community business members, stated that they feel that the students can be hired to be trained on other 
network operating systems because their potential to learn is expressed in their ability to pass the Novell Certified NetWare Administrators exam. The board's recommended changes to the course structure include an addition of more recent hardware, additional hardware to bring in more topologies, and a larger lab room.

Table 1

\begin{tabular}{|l|l|}
\hline & \multicolumn{1}{|c|}{ Laboratory Activities } \\
\hline Week 1 & $\begin{array}{l}\text { Inspect a network setup and familiarize students with network } \\
\text { configurations }\end{array}$ \\
\hline Week 2 & Dismantle a computer system and add network hardware \\
\hline Week 3 & $\begin{array}{l}\text { Investigate different network configurations and topologies } \\
\text { available on campus }\end{array}$ \\
\hline Week 4 & $\begin{array}{l}\text { Install network software on preassembled network hardware } \\
\text { setups }\end{array}$ \\
\hline Week 5 & Install network hardware and software on standalone computers \\
\hline Week 6 through week 8 & $\begin{array}{l}\text { Make cables and cable connectors; connect computers used as } \\
\text { workstations with cables; install network software }\end{array}$ \\
\hline Weeks 7 through week 10 & Add users, network security, and manage usage and workgroups \\
\hline Weeks 11 through 15 & $\begin{array}{l}\text { Add printers, application programs, add more security, administer } \\
\text { and maintain networks, practice troubleshooting the network }\end{array}$ \\
\hline
\end{tabular}

Table II

\begin{tabular}{|l|l|}
\hline & \multicolumn{1}{|c|}{ Theoretical Concepts } \\
\hline Weeks 1 through 3 & Physical Layer examined \\
\hline Weeks 2 and 3 & Data Link Layer examined \\
\hline Week 3 & Network Layer examined \\
\hline Week 4 and weeks 7 through 11 & Transport Layer \\
\hline Week 7 through 15 & Session Layer \\
\hline Weeks 11 through 15 & Presentation Layer \\
\hline Weeks 11 through 15 & Application Layer \\
\hline
\end{tabular}

Table III 


\begin{tabular}{|l|l|}
\hline & \multicolumn{1}{|c|}{ Specifications for Hardware, Software and Groups } \\
\hline Hardware & $\begin{array}{l}\text { four 486 computers for servers with CD-ROM, 8 Mb RAM: eight } \\
286 \text { computers for workstations: three dot-matrix printers, one laser } \\
\text { printer }\end{array}$ \\
\hline Software & $\begin{array}{l}\text { Novell NetWare 4.1, Windows 3.11, a variety of application } \\
\text { packages }\end{array}$ \\
\hline Network Topology & Ethernet using a bus topology with coaxial cable \\
\hline Group Size & 2 students per group \\
\hline Group Equipment & $\begin{array}{l}\text { Use of a file server, a workstation, NetWare 4.1 OS on a CD-ROM } \\
\text { and workstation software on a diskette, interface card and cables } \\
\text { with terminators }\end{array}$ \\
\hline Reference Book & Novell Study Guide by New Riders \\
\hline
\end{tabular}

\section{References}

1. Bierer, Cady, Heywood, Niedermiller-Chaffins, and Steen, Novell CNE 4 Study Guide, New Riders, 1996, pp. 1-208

2. Cady, Heywood, Homer, Dullness, Aren't, and Niedermiller-Chaffins, CNE Short Course, New Riders

Publishing, 1995, p. 148

3. Case and Smith, Managing Local Area Networks, D.McGraw-Hill, 1995, p. 181

4. Gilbert, Understanding Data Communications, Sams Publishing, 1996, p. 311

5. Gohring and Jasper, PC-Host Communications: Strategies for Implemention, Addison-Wesley, 1993

6. Harris, Lan Basics with Hands-On Netware, McGraw-Hill, 1995

7. $\quad$ King, "Survey Says: Certify, Certify", ComputerWorld, 1996 Jan 22, p. 59.

8. Laplante, "LAN/WAN Skills Sought After in IS Shops", Infoworld, 1992 June 8

9. Midgley, Bruce, Shepard, Lil, Hospital "How to Create Imagineering Employees", Materiel Management Quarterly, 1996 Aug., pp. 28-39

10. Robert Hernandez, Enterprise Network Engineer, Texas Engineering Extension Service, The Texas A\&M Unversity System, Institute of Electronic Science

11. Stamper and the Saratoga Group, Essentials of Data Communications, Benjamin Cummins, 1997, p.16

DOMINGO MOLINA III is an assistant professor, a Novell Certified Netware Administrator and a Certified Netware Engineer. He is currently the chair of the Computer Science and Computer Information Systems Department, a position he has held for six years. His interests include networks, operating systems and data structures. 